\title{
Estado e Educação: o desafio de ampliar a cidadania
}

\section{State and Education: the challenge to enlarge citizenship}

\author{
Pedro Roberto Jacobi*
}

\begin{abstract}
RESUMO
$\mathrm{O}$ artigo aborda o tema da participação como um processo continuado de democratização da gestão da educação. Está estruturado em três partes. Inicialmente, desenvolve-se uma reflexão sobre o conceito de participação em suas diversas dimensões e possibilidades. A segunda parte enfoca os públicos participativos no Brasil privilegiando a institucionalização das relações entre o Estado e a sociedade civil. A terceira parte se centra nas possibilidades de construção de espaços de inovação institucional. As experiências explicitam a existência/inexistência de um potencial de ruptura em torno da distância quase sempre presente entre o poder centralizado e as realidades sociais mutantes e heterogêneas. Isto põe em evidência os limites dos mecanismos existentes formais, verticais, corporativos e clientelistas, construídos para permitir/impedir a participação dos cidadãos nos assuntos públicos. O principal desafio está em fortalecer espaços deliberativos e a modernização dos instrumentos de gestão e de articulação. Para tanto, requer-se uma engenharia sócio-institucional pautada pela premissa da superação das barreiras socioinstitucionais existentes e o necessário fortalecimento na sociedade de políticas pautadas pela inclusão da noção de interesse geral. Isto se potencializa na medida em que o tema da cidadania é assumido como um ponto nodal para a institucionalização da participação dos cidadãos em processos decisórios de interesse público no contexto das políticas educacionais, assim como aquelas que com ela se relacionam e são interdependentes.

Palavras-chave: Estado, educação, cidadania, participação.
\end{abstract}

* Professor Titular da Faculdade de Educação da Universidade de São Paulo. E-mail: prjacobi@usp.br. 


\begin{abstract}
The article approaches the theme of participation as a continuous process of democratization of educational administration. It is structured in three parts. Initially it develops an analysis on the concept of participation in its diverse dimensions and possibilities. The second part focuses on a participatory public in Brazil with emphasis in the institutionalization of the relations between State and Civil Society. The third part concentrates on the possibilities of constructing areas of institutional innovation. Experiences indicate the existence/inexistence of a potential rupture of the existing distance, which almost always presents a centralized power and mutant and heterogeneous social realities. This puts into evidence the limits of existing mechanisms; formal, vertical, corporative and clientelistic, which were built to allow/prevent the participation of citizens in public issues. The main challenge is to strengthen deliberative areas and modernize the instruments of management and articulation. Thus, socio-institutional engineering is required based on the premise to overcome of the existing socio-institutional barriers and the necessary development within society of public policies centered on the notion of general interest. This may be promoted as the theme of citizenship and is considered very relevant towards the effective institutionalization of participation of citizens in the decision making processes of public interest within educational policies, and as well as those that are related to and intertwined with it.
\end{abstract}

Key words: State, education, citizenship, participation.

\title{
Participação, capital social e cidadania
}

O conceito de participação está associado à democracia deliberativa e à existência de uma esfera pública. Isto pode ser entendido como parte do vínculo histórico da democracia com a criação de novos direitos. Precisamos nos remeter ao referencial teórico (MARSHALL, 1967), que reflete sobre a sucessiva criação e expansão dos direitos dos cidadãos na sociedade moderna. A constituição de direitos civis, políticos e sociais baseia-se no exercício de práticas de cidadania que garantem a sua liberdade como cidadãos. As diferenças entre as sociedades modernas são significativas. Enquanto algumas sociedades avançaram muito, notadamente nos estados de bem-estar social, na maioria dos países, as desigualdades materiais impedem a efetiva realização de liberdades. A isto acrescentam-se os déficits de formação política de opinião e da possibilidade de efetiva participação nos processos decisórios. Embora afirmar que a 
participação dos cidadãos é componente fundamental de uma forma democrática de governo seja praticamente uma obviedade, existem diversos aspectos que devem ser considerados.

As leituras são diversas e principalmente desde o início da década de 1980, no Brasil e na América Latina, a partir da volta da vigência das instituições democráticas formais básicas. O avanço do processo de construção democrática contribui para fortalecer uma visão sobre construção de cidadania e participação. Estas assumem um papel estratégico na compreensão da formação de novas identidades no contexto societal, assim como da emergência de novas formas de ação coletiva.

O processo de construção da cidadania é marcado por paradoxos na medida em que se explicitam três dinâmicas concomitantes: o reconhecimento e a construção das identidades dos distintos sujeitos sociais envolvidos; o contexto da inclusão das necessidades expressas pelos distintos sujeitos sociais; e a definição de novas agendas de gestão. Estes aspectos se referem, notadamente, quanto à extensão dos bens a amplos setores da população (universalidade e eqüidade).

Esse complexo processo em um contexto de agudização das desigualdades é perpassado por um conjunto de questões que necessariamente implicam na superação das bases constitutivas das formas de dominação e da cultura política que em muitos casos ainda coexistem. A participação da sociedade civil na gestão pública introduz uma mudança qualitativa na medida em que incorpora outros níveis de poder além do Estado; e isto se configura como um direito ao autodesenvolvimento que pode ser alcançado numa sociedade participativa contribuindo para a formação de uma cidadania qualificada.

A década de 1990 se caracteriza por um movimento muito intenso de forças sociais engajadas em práticas que demandam participação, denominadas de Públicos Participativos, por Habermas (JACOBI, 2000). Esse conceito agrega cidadãos que se organizam para enfrentar a exclusão social e política através da deliberação pública. A premissa central é a existência de espaços públicos - encontros abertos e públicos, que representam os instrumentos essenciais para melhorar a vida democrática através da ampliação da presença de atores sociais que representam a diversidade e heterogeneidade da nossa sociedade.

Na década de 1990, a participação nas suas diversas dimensões foi amparada e institucionalizada na América Latina dentro dos marcos das democracias representativas. A participação popular se transforma no referencial de ampliação das possibilidades de acesso dos setores populares na perspectiva do desenvolvimento da sociedade civil e do fortalecimento dos mecanismos democráticos. Entretanto, observa-se que no geral as propostas participativas ainda permanecem mais no plano da retórica do que no da prática. 
A participação deve ser entendida como um processo continuado de democratização da vida dos cidadãos, e seus objetivos são: 1) promover iniciativas a partir de programas e campanhas especiais visando ao desenvolvimento de objetivos de interesse coletivo; 2) reforçar o tecido associativo e ampliar a capacidade técnica e administrativa das associações; 3) estimular a participação na definição de programas e projetos de interesse coletivo, nas suas diversas possibilidades.

O surgimento de políticas públicas pautadas pelo componente participativo está relacionado com as mudanças na matriz sociopolítica através de um maior questionamento sobre o papel do Estado como principal agente indutor das políticas sociais. A noção de participação é pensada principalmente a partir da ótica dos grupos interessados e não apenas da perspectiva dos interesses globais definidos pelo Estado (AVRITZER, 2002, COSTA, 2002, JACOBI, 2000), e não apenas da perspectiva dos interesses globais definidos pelo Estado.

O principal problema que se coloca é o de se construir uma ordem societária baseada na articulação da democracia política com a participação social representada por uma maior permeabilidade da gestão às demandas dos diversos sujeitos sociais e políticos. Essa perspectiva abre a possibilidade de se pensar a articulação entre a implantação de práticas descentralizadoras e uma engenharia institucional que concilia participação com heterogeneidade e formas mais ativas de representatividade, reforçando a reciprocidade diante da dimensão de organização molecular da sociedade.

A formulação mais recorrente está estruturada em torno do aprofundamento do processo democrático, e do seu impacto na ampliação da capacidade de influência sobre os diversos processos decisórios em todos os níveis da atividade social e das instituições sociais. Nesse sentido, a participação social se caracteriza como um importante instrumento de fortalecimento da sociedade civil, notadamente dos setores mais excluídos, na medida em que a superação das carências acumuladas depende basicamente da interação entre agentes públicos e privados no marco de arranjos socioinstitucionais estratégicos. A participação social se enquadra no processo de redefinição entre o público e o privado, dentro da perspectiva de redistribuir o poder em favor dos sujeitos sociais que, geralmente, a ele não têm acesso.

A efetiva participação requer princípios para o desenvolvimento da legitimidade democrática: a igualdade e o pluralismo políticos, a deliberação e a solidariedade. Assim, pode-se afirmar que, apesar de alguns avanços, a participação cidadã associada a um projeto de ampliação da esfera pública depende da capacidade de cada sociedade de ampliar a institucionalidade pública e fortalecer a comunidade cívica. 
O tema da participação também dialoga com o conceito de capital social. Este é definido como o conjunto de normas sociais e redes de cooperação e de confiança, e também das instituições e práticas culturais que dão intensidade e qualidade à dimensão das relações interpessoais num processo participativo que permeia 0 desenvolvimento de políticas públicas.

Ao longo dos últimos anos, o conceito de capital social se tornou extremamente difundido entre sociólogos, cientistas sociais e profissionais ligados às áreas de desenvolvimento. Este conceito pode ser dividido em duas grandes correntes, uma focada nas relações que um ator mantém com outro(s) ator(es) e outra focada nas relações internas e externas de uma organização.

A primeira categoria, mais comum entre sociólogos, salienta a idéia de que as ações dos indivíduos podem ser fortemente enaltecidas através da sua participação em redes sociais, especificamente através das interações diretas e indiretas com os outros atores desta rede. Nessa concepção, capital social está relacionado aos recursos e benefícios potenciais que um ator tem, por possuir ou participar de uma rede sólida e durável de relações pessoais (BOURDIEU, 1985; COLEMAN, 1988, PORTES, 1998).

Em contraste com essa visão individualizada sobre capital social há uma outra corrente de autores que analisa o capital social a partir das redes de atores coletivos. Nessa perspectiva, o capital social é visto como um bem social, resultante das conexões e acesso dos atores sociais aos recursos existentes nas redes ou grupos dos quais fazem parte que lhes garantem a coesão necessária para atingir os resultados esperados. Essa perspectiva é comumente difundida entre cientistas políticos e economistas do desenvolvimento (LIN, 2001, PUTNAM, 1996, WOOLCOCK, 1998, OSTROM 1990, UPHOFF, 2000). Inúmeras experiências práticas já demonstraram que não considerar a dimensão social nos processos de desenvolvimento, como normas, costumes, cultura, valores, motivação ou solidariedade, levou a resultados pouco desejáveis ou até mesmo a enormes fracassos.

Entretanto, de forma geral, há um consenso na literatura, de que capital social refere-se à habilidade que os atores desenvolvem de garantir benefícios através de associação em redes de relações sociais ou outras estruturas sociais.

Durante a década de 1990, diversos autores discutiram mais especificamente a questão da autonomia do Estado e os efeitos da dispersão das instituições públicas. Putnam (1996) e Evans (1995) incorporaram o conceito de capital social e debateram o papel das instituições na indução de mudança social, indicando o esgotamento dos dois eixos paradigmáticos principais da intervenção pública: o neoliberalismo e o desenvolvimentismo clássico. Para Evans (1995), os componentes que formam o capital social, entre os quais estão o engajamento cívico, a integração social e as normas de confiança, podem ser promovidos pelas esferas governamentais e, inclusive, podem ser utilizados com vistas ao desenvolvimento. 


\section{Espaços participativos no Brasil}

No Brasil, o tema das políticas sociais e das desigualdades sociais deve ser analisado como elemento constitutivo da cidadania de sujeitos sociais coletivos.

Quando se fala de "participação dos cidadãos", deve-se enfatizar tratar-se de uma forma de intervenção na vida pública com motivação social concreta que se exerce de forma direta, baseada num certo nível de institucionalização das relações Estado/Sociedade.

A análise das práticas participativas centra o fortalecimento do espaço público e a abertura da gestão pública à participação da sociedade civil na elaboração de suas políticas públicas; e à sempre complexa e contraditória institucionalização de práticas participativas inovadoras que marcam rupturas com a dinâmica predominante, ultrapassando as ações de caráter utilitarista e clientelista (AVRITZER, 2002; COSTA, 1994; COSTA, 2002). Está permeada pelos condicionantes da cultura política, tanto no Brasil como nos outros países da América Latina, marcados por tradições estatistas, centralizadoras, patrimonialistas.

Com as mudanças político-institucionais que ocorrem a partir de meados dos anos de 1980, os movimentos passam a enfrentar a tensão ante à institucionalização, configurada a partir da sua desconfiança quanto à participação política no jogo institucional, na defesa de um associativismo ingênuo e intransigente, assim como por seu visível perfil corporativista. Muitos movimentos apontam, a partir da reposição do coletivo, para uma qualidade diferenciada de participação na gestão da coisa pública. A representação não resume todo o esforço de organização, mas configura uma parte de um processo em que a população cria as condições para influenciar a dinâmica de funcionamento de um órgão do Estado. Torna-se manifesta uma identidade concretizada a partir da construção coletiva de uma noção de direitos que, relacionada diretamente com a ampliação do espaço de cidadania, dá lugar ao reconhecimento público das carências.

Nos anos de 1990, além das práticas participativas inovadoras que se institucionalizam cada vez mais, surgem novos movimentos baseados em ações solidárias alternativas centradas em questões éticas ou de revalorização da vida humana.

Essas mudanças representam, segundo Melucci (1994), o fortalecimento de novas instituições, as mudanças no relacionamento do quadro de pessoal com os usuários e a nova mentalidade sobre a gestão da coisa pública, enquanto aspectos constitutivos de uma nova cultura política. 
A formulação mais recorrente está estruturada em torno do aprofundamento do processo democrático e do seu impacto na ampliação da capacidade de influência sobre os diversos processos decisórios em todos os níveis da atividade social e das instituições sociais. Nesse sentido, a participação social, que se caracteriza como importante instrumento de fortalecimento da sociedade civil, depende basicamente da interação entre agentes públicos e privados no marco de arranjos socioinstitucionais estratégicos. Configura-se como um instrumento de socialização da política e reforça seu papel enquanto meio para realizar interesses e direitos sociais que demandam uma atuação pública.

Os movimentos sociais, ao se organizarem e demandarem direitos, mostram a necessidade de compatibilização entre modernização econômicoadministrativa e cidadania (JACOBI, 2000). Isto ocorre à medida que o seu impacto na constituição de uma arena societária em expansão lhes permite perceber que a multiplicação de práticas democratizantes pode gerar mudanças nas suas vidas cotidianas.

A consolidação de propostas participativas representa a potenciação e a ampliação de práticas comunitárias, através do estabelecimento e da ativação de um conjunto de mecanismos institucionais que reconheçam direitos efetivamente exercíveis e estimulem estratégias de envolvimento e co-responsabilização. Um dos maiores desafios de uma proposta participativa ampliada é garantir a definição de critérios de representação, de forma a impedir tanto a sua manipulação por grupos criados para defender interesses particularizados, quanto a possibilidade de sua má instrumentalização pela administração pública.

A análise da experiência brasileira mostra o desafio que se coloca para garantir a eficácia e a continuidade de políticas públicas. A descontinuidade das políticas públicas reforça o argumento de que a gestão democrática e a participação popular requerem uma forma combinada de fortalecimento das formas de organização da sociedade civil, uma mudança na correlação de forças e uma transformação qualitativa dos padrões de gestão. Tal transformação demanda o que Arato e Cohen (1994) definem como a existência de uma sociedade civil organizada, diferenciada e capaz de influenciar o Estado para garantir a manutenção de direitos essenciais, e de monitorar e influenciar os processos que se regulam pela lógica sistêmica. Mas também mostra que os processos são lentos e não necessariamente unidirecionais.

A participação da população nos processos decisórios requer um esforço crescente de institucionalização da possibilidade de atendimento às demandas em bases negociadas. Trata-se de processar demandas e pressões, e de implementar mecanismos formais que contemplem os setores organizados e mobilizados, estimulando sua adequação à institucionalidade e respeitando sua autonomia e auto-organização. 
As dimensões diferenciadas de participação mostram a importância das diferentes engenharias institucionais. Os complexos e desiguais avanços revelam que essas engenharias institucionais - baseadas na criação de condições efetivas para multiplicar experiências de gestão participativa que o significado da publicização das formas de decisão, e de consolidação de espaços públicos democráticos - ocorrem pela superação das assimetrias de informação e pela afirmação de uma nova cultura de direitos. Estas experiências inovadoras fortalecem a capacidade de crítica e de participação dos setores de baixa renda, através de um processo pedagógico e informativo de base relacional, assim como a capacidade de multiplicação e aproveitamento do potencial dos cidadãos no processo decisório dentro de uma lógica cooperativa.

A realidade brasileira é caracterizada pela pouca mobilização do sua população para explicitar uma disposição de utilizar os instrumentos da democracia participativa. Acrescente-se o fato de a maioria das organizações sociais se constituírem em representações relativamente frágeis, ou extremamente especializadas, tendendo a estabelecer relações particularizadas e diretas com a administração pública local. Os grupos organizados, que interagem e pressionam, representam iniciativas fragmentárias que não atingem o cerne de uma sociedade refratária a práticas coletivas. A experiência brasileira traz à tona as ambigüidades e as possibilidades que se colocam para a democratização progressiva da atuação de um Estado enquanto agente de controle ou participação. Referimo-nos, notadamente, à sua capacidade de criar um ambiente facilitador capaz de mobilizar energias e recursos da sociedade, estimular diversos tipos de parcerias e garantir a implantação de políticas que privilegiem um estreito relacionamento entre eqüidade e participação.

Os desafios para ampliar a participação estão intrinsecamente vinculados à predisposição dos governos locais de criar espaços públicos e plurais de articulação e participação, nos quais os conflitos se tornem visíveis e as diferenças se confrontem enquanto base constitutiva da legitimidade dos diversos interesses em jogo (AVRITZER, 2002; COELHO e NOBRE, 2004; MELO et al, 2005). Isto coloca a necessidade de se ter como referência uma engenharia institucional legítima aos olhos da população, que garanta espaços participativos transparentes e pluralistas numa perspectiva de busca de eqüidade e justiça social, configurada pela articulação entre complexidade administrativa e democracia.

A realidade social deste início de século apresenta um mosaico caótico no qual também se inscreve o Brasil. A dimensão da cidadania está ancorada numa participação ativa no processo público e nos aspectos simbólicos e éticos apoiados em fatores subjetivos que conferem um sentido de identidade e de pertencimento. 
As possibilidades de reverter de forma significativa o atual quadro estão associadas, de um lado, à necessidade de uma reinvenção solidária e participativa do Estado. De outro, à difícil tarefa das organizações da sociedade civil, num contexto de erosão de direitos, de consolidar práticas que fortaleçam a sua capacidade de interlocução na definição de políticas públicas e na partilha dos recursos provenientes dos fundos públicos.

A participação deve ser entendida como um processo continuado de democratização da vida pública, com uma motivação social concreta que se exerce de forma direta, e método de governo centrado na institucionalização das relações entre o Estado e a sociedade civil. As experiências explicitam a existência/inexistência de um potencial de ruptura em torno da distância quase sempre presente entre o poder centralizado e as realidades sociais mutantes e heterogêneas. Isto põe em evidência os limites dos mecanismos existentes formais, verticais, corporativos e clientelistas, construídos para permitir/impedir a participação dos cidadãos nos assuntos públicos. Estes limites foram mantidos/ superados por algumas administrações municipais progressistas. Estas assumiram o risco calculado de abrir canais de interação com os movimentos sociais organizados e os novos atores políticos que questionam práticas tuteladas, e buscam consolidar de forma partilhada novas formas de representação, organização e cooperação. Nesse sentido, e em face da extrema urgência no atendimento às múltiplas demandas sociais dos setores mais excluídos, a participação se fortalece através do estímulo às práticas dialógicas permanentes baseadas em regras de reciprocidade e transformação sociocultural na dinâmica assimétrica que caracteriza as relações entre Estado e Sociedade.

A ruptura com a cultura política dominante, e para uma nova proposta de sociabilidade baseada na educação para a participação, vai se concretizar principalmente pela presença crescente de uma pluralidade de atores. Através da ativação do seu potencial de participação, terão cada vez mais condições de intervir consistentemente e sem tutela nos processos decisórios de interesse público.

\section{Possibilidades de construção de espaços de inovação institucional}

Dados do Sistema de Informações dos Conselhos Municipais de Educação (Sicme), que traça o perfil dos Conselhos e dos conselheiros em todo o país, mostram que mais de $30 \%$ dos conselhos municipais de educação no Brasil têm 
como presidente o próprio secretário de educação ou uma pessoa indicada pelo prefeito. Esta é uma das conclusões de uma pesquisa sobre o Perfil dos Conselhos Municipais de Educação, realizada pela Secretaria de Educação Básica do Ministério da Educação (MEC). De acordo com a pesquisa, dos 5.561 municípios brasileiros, 56\% não têm conselhos; em 64\% dos municípios onde o conselho existe, o presidente é eleito por um colegiado; em $22 \%$, o presidente é o secretário de Educação; e em 10\% o titular é indicado pelo prefeito. Os $2 \%$ restantes indicaram outros meios de escolha. Essas instâncias de gestão compartilhada são fundamentais para a qualidade da educação, pois fiscalizam os municípios na hora de gastar os recursos para a compra da merenda e transporte escolar. Segundo o MEC, muitos municípios desativam os conselhos por falta de capacitação dos conselheiros, por dificuldade de acesso à legislação educacional ou pela falta de preparo para interpretação dessas leis.

Esses dados mostram uma situação que muitas vezes tem sido escamoteada; a constituição de fóruns participativos na gestão da coisa pública com efetivo engajamento, além dos chamados "setores participativos" da sociedade civil, tem ainda pouco impacto na democratização da gestão.

Algumas experiências inovadoras, como a de São Paulo entre 1989 e 1992 (JACOBI, 2000), revelaram que a dinamização das instâncias participativas, apesar da resistência do funcionalismo, possibilitaram avanços na autonomia administrativa, financeira e pedagógica das escolas. Os alcances da participação, apesar do estímulo da Administração, estavam muito relacionados ao nível de mobilização, organização e pressão existentes nos bairros. Os Conselhos de Escola foram incentivados pela Administração e seus resultados foram diversificados, principalmente pela inexistência de um ethos efetivamente participativo na população. O desafio colocado era romper com as relações de poder existentes, valorizando e resgatando a noção de escola, acomodando a demanda e estimulando mecanismos de co-responsabilização da população na dinâmica da gestão, motivando o protagonismo dos setores mais excluídos. A lógica hierarquizada gerou dificuldades no nível organizacional e as resistências se centravam, principalmente, no preconceito e no questionamento, pelo corpo diretivo e docente, sobre o caráter deliberativo dos Conselhos e a descentralização do poder, revelando resistência em dividir o poder. Entretanto, cabe ressaltar que, no geral, a participação estava muito vinculada à noção de utilidade/ objetividade daquilo que era discutido e proposto, refletindo as dificuldades de se romper com a cultura política predominante, apesar do esforço da gestão em introduzir uma nova qualidade do trabalho na educação. A iniciativa de abrir canais de participação criava espaço para um importante questionamento da relação Estado e Sociedade. Em primeiro lugar, fez emergir a necessidade de a comunidade - através de suas formas organizativas e representativas - enfrentar 
sua relação com as propostas de participação implantadas pela Administração, dentro do conceito de democratizar e inovar na gestão da coisa pública. As dinâmicas de participação implantadas possibilitaram um aumento do grau de informação sobre o funcionamento dos serviços e da Administração. Isto reforçava a sua razão de ser enquanto instâncias com bases setoriais e territoriais, de concretização de um exercício de controle mais permanente e consistente da coisa pública pelos usuários, e representava uma referência de inovação e de construção de novas identidades dos atores sociais envolvidos. A consolidação de práticas participativas que potencializam conquistas materiais para os mais desiguais entre os desiguais mostra os alcances que a criação de um espaço público não-estatal pode promover enquanto arena democrática de negociação entre o Estado e a Sociedade, como principal pressuposto para a governabilidade e a legitimidade.

Diversos estudos (TATAGIBA, 2002; GOHN, 2001; LUBAMBO e COELHO, 2005; LUBAMBO e COUTINHO, 2004; TEIXEIRA, 2004; JACOBI, 2000) mostram a complexidade das práticas e os impactos das políticas permeadas por uma concepção democrática de gestão. Estas têm na dimensão participativa, com a presença de uma pluralidade de atores e interesses organizados, a base argumentativa sobre os alcances e limites da participação.

O principal exemplo são os diferentes tipos de conselhos gestores de políticas públicas (saúde, educação, assistência social), que apontam para a existência de um espaço público de composição plural e paritária entre Estado e sociedade civil, de natureza deliberativa. Considerando-se que praticamente todos os municípios do país têm conselhos de saúde e educação, tem-se um importante contingente de cidadãos e cidadãs envolvidos em práticas participativas co-responsabilizadoras. Apesar de os conselhos gestores representarem arranjos institucionais inovadores, a grande indagação está relacionada com a capacidade de traduzir-se em práticas inovadoras e de uma efetiva democratização nos procedimentos de gestão dos assuntos públicos. (TATAGIBA, 2002)

Lubambo e Coutinho (2004) mostram que existe unanimidade em torno da idéia de que a participação concreta dos segmentos populares no processo decisório é condição básica para a efetivação da gestão. Dessa forma, os recursos seriam destinados com mais eficiência, o que aumentaria o controle social. $\mathrm{O}$ fortalecimento dos mecanismos de controle de políticas setoriais amplia as possibilidades de constituição de sujeitos democráticos na interlocução com as políticas públicas, promovendo co-responsabilização.

Os estudos mostram que a participação implica muito mais que a constituição de atores que participam, mas a explicitação de cidadãos críticos e problematizadores, no que se convencionou denominar cidadãos de uma sociedade reflexiva (BECK, 1997), que se contrapõem aos que atuam numa visão utilitarista 
e imediatista. Isto representa a possibilidade de se consolidar um aprendizado social, baseado no diálogo e interação em constante processo de recriação e reinterpretação de informações, conceitos e significados, que fortalecem a capacidade de diálogo e articulação organizacional dos atores envolvidos.

Cabe destacar alguns aspectos que garantem a institucionalização da participação. O grau de eficácia e efetividade no âmbito das ações de um programa ou de uma política setorial depende de algumas condições (MELO, 2003). Destacam-se o nível de legitimidade e representatividade política dos membros; a efetiva disponibilidade de recursos para o setor ou programa envolvido; o grau de socialização das informações; o grau de compromisso com o empoderamento dos beneficiários; e a capacidade de acomodação de conflitos entre os atores envolvidos. Isto traz à tona a dimensão institucional e, notadamente, a consolidação de práticas participativas e sua efetiva implementação enquanto espaços deliberativos e com ampla representatividade. Contudo, a principal questão no elenco dos limites relaciona-se à identificação dessas instituições nomeadas de instrumentos de controle e participação social como portadoras de real significado representativo. Isto nos remete à dificuldade de se distinguir, empiricamente, entidades de papel daquelas orgânicas de fato, quando a tradição, a prática e o registro do controle social são ainda embrionários no país.

O que se observa é que ainda é muito restrito o número de municípios que dispõe das condições necessárias para assumir um papel inovador e eficiente, baseado em mais participação social e democratização na gestão das políticas públicas. A realidade mostra que a maioria ainda se caracteriza como sendo desprovida de condições mínimas de sustentação, configurando-se, portanto, a sua dependência, tanto do governo estadual quanto do federal. A falta de um efetivo sistema de avaliação revela a ainda restrita capacidade técnica e administrativa de estados e municípios, principalmente dos mais pobres, para atender os critérios de habilitação exigidos para uma gestão mais adequada. O fato de a imensa maioria dos municípios pobres serem quase totalmente desprovidos de pessoal qualificado para realizar as atividades orçamentárias básicas mostra as dificuldades existentes para estabelecer um equilíbrio no relacionamento intergovernamental.

Entretanto, nos municípios onde avança o processo de descentralização, verifica-se um forte estímulo à participação por parte da comunidade, sendo que a autonomia na gestão dos recursos financeiros tem sido o principal elemento valorizador do processo decisório no nível local.

$\mathrm{Na}$ educação, as dificuldades na implantação e monitoramento do FUNDEF revelavam a complexidade de implementar políticas efetivamente descentralizadoras visando a redução das desigualdades sociais. As dificuldades dos estados para organizar seus sistemas de ensino, assim como dos municípios, revelam 
a carência de recursos e de capacidade técnica. A progressiva transferência de encargos para os municípios tem gerado uma situação contraditória. As pesquisas mostram que a experiência dos conselhos é ainda bastante controversa, e sua capacidade operacional, restrita, na medida em que se observa dificuldade de acesso à legislação educacional e falta de preparo para interpretação das leis. (TEIXEIRA, 2004)

O principal desafio está em fortalecê-los enquanto espaços deliberativos e na modernização dos instrumentos de gestão e de articulação. Para tanto, exige-se uma engenharia socioinstitucional complexa, apoiada em processos educativos para garantir condições de acesso às informações e impactos da atuação local, notadamente nos grupos sociais mais vulneráveis. Num contexto de significativa desmobilização da sociedade em geral, coloca-se a necessidade de multiplicar as iniciativas pautadas pela ampliação do direito à informação numa perspectiva integradora, e de fortalecer as práticas de formação da cidadania. É preciso o engajamento de um maior número de pessoas em práticas coresponsabilizadas de gestão da coisa pública, enquanto portadores de um papel social que se constitui através da criação de espaços sociais de mobilização, e na institucionalização de práticas de cidadania ativa que garantam a expressão e representação de interesses coletivos.

Isto demanda a superação das barreiras socioinstitucionais existentes e o necessário fortalecimento na sociedade de políticas pautadas pela inclusão da noção de interesse geral. A sua concretização se potencializa na medida em que o tema da cidadania é assumido como um ponto nodal para a institucionalização da participação dos cidadãos em processos decisórios de interesse público.

\section{REFERÊNCIAS}

ARATO, A.; COHEN, J. Sociedade civil e teoria social. In: AVRITZER, L. Sociedade civil e democratização. Belo Horizonte: Del Rey, 1994. p. 147-182.

AVRITZER, L. Democracy and the Public Space in Latin America. Princeton: Princeton University Press, 2002.

BECK, U. Modernização reflexiva. São Paulo: Unesp, 1997.

COElho, V.; NOBRE, M. (Org.). Participação e deliberação. São Paulo: Editora 34, 2004. 
COSTA, S. Esfera pública, sociedade civil e movimentos sociais no Brasil. Revista Novos Estudos CEBRAP, São Paulo, v. 38, p. 38-52, 1994.

COSTA, S. As cores de Ercília. Belo Horizonte: Editora UFMG, 2002.

DAGNINO, E. Os movimentos sociais e a emergência de uma nova noção de cidadania. In: DAGNINO, E. (Org.). Politica e sociedade no Brasil. São Paulo: Brasiliense, 1994. p. 103-118.

DOIMO, A. A vez e a voz do popular. Rio de Janeiro: ANPOCS/Relume Dumará, 1995.

GOHN, M. G. Conselhos gestores e participação sociopolítica. São Paulo: Cortez, 2001.

JACOBI, P. R. Descentralização municipal e participação dos cidadãos: apontamentos para o debate. Lua Nova, São Paulo, v. 20, p. 121-144.

. Políticas sociais e ampliação da cidadania. Rio de Janeiro: FGV, 2000.

LUBAMBO, K.; COUTINHO, H. Conselhos gestores e o processo de descentralização. São Paulo em Perspectiva, São Paulo, SEADE, v. 18, n. 4, p. 62-72, 2004.

LUBAMBO, K.; COELHO, D. Governo e sociedade civil aprendem: o que revela a experiência recente de participação em Pernambuco. In: MELO, M. et al. Desenho institucional e participação política. Petrópolis: Vozes, 2005. p. 256-297.

MELO, M. Crise federativa, guerra fiscal e hobbesianismo municipal: efeitos perversos da descentralização. Revista São Paulo em Perspectiva, São Paulo, SEADE, v. 10, n. 3, p. 11-20, 1996.

. Empowerment e governança no Brasil: questões conceituais e análise preliminar de experiências selecionadas. Background paper. World Bank - Brazilian Office Draft, 2003.

MELO, M. et al. Desenho institucional e participação política. Petrópolis: Vozes, 2005.

MELUCCI, A. Movimentos sociais, renovação cultural e o papel do conhecimento. Entrevista concedida a L. Avritzer e T. Lyyra. Revista Novos Estudos CEBRAP, São Paulo, v. 40, p. 152-166, 1994.

PUTNAM, Robert. Making Democracy Work. Princeton University Press, Princeton, 1993. 
TATAGIBA, L. Os Conselhos Gestores e a democratização das políticas públicas no Brasil. In: DAGNINO, E. (Org.). Sociedade civil e espaços públicos no Brasil. São Paulo: Paz e Terra, 2002. p. 47-103.

TELLES, V. Sociedade civil e a construção de espaços públicos. In: DAGNINO, E. (Org.). Anos 90: política e sociedade no Brasil. São Paulo: Brasiliense, 1994. p. 91102.

TEIXEIRA, L. Conselhos municipais de educação: autonomia e democratização do ensino. Cadernos de Pesquisa, São Paulo, v. 34, n. 123, p. 691-708, 2004.

Texto recebido em 5 set. 2007 Texto aprovado em 18 nov. 2007 